\title{
The Implications of Trust on Nursing Team Contextual Performance: A Evidence from Malaysia
}

\author{
Azlyn Ahmad Zawawi ${ }^{1}$ \\ ${ }^{I}$ Faculty of Administrative Science and Policy Studies, University Teknologi MARA
${ }^{*}$ Corresponding author. Email: azlyn@ @edah.uitm.edu.my
}

\begin{abstract}
Successful service-oriented organizations are made of proficient employees who are willing to give their best to achieve the organizations' objectives either as an individual or part of a team. The use of teams to accomplish tasks denotes that the members are more energetic, synergized, and active in collective surroundings. Nurses in particular, are highly dependent on teams because high-performing nursing teams will lead to a higher degree of members' satisfaction, decreased stress, increased quality of healthcare, reduced medical errors, and increased patient safety. Based on that notion, this study sought to examine the indirect relationship between team leaders' transformational leadership, team support and team contextual performance via the mediating role of team trust. Team contextual performance was conceptualized as the activities that affect the organization's social and psychological environment, such as teammates' helping behavior, acceptance towards suggestions or criticisms, and cooperation. A total of 1436 individual nurses (300 nursing teams) from seven healthcare institutions in Malaysia participated in this study. Data were collected using two sets of questionnaires which were distributed to the team leaders and team members respectively. Individual responses were combined and data were then merged and aggregated to the team level to get the team's final score. Analysis of the hypotheses were done using Partial Least Squares (PLS) and results indicated that team trust mediates the relationship between perceived team support and team contextual performance $(\beta=0.175, p<0.01)$. The results from the mediation analysis also showed that team trust mediates the relationship between transformational leadership and team contextual performance $(\beta=0.057, \mathrm{p}<0.05$. Discussion on the findings is provided.
\end{abstract}

Keywords: Perceived Team Support, Malaysia, Team Contextual Performance, Transformational Leadership

\section{INTRODUCTION}

Studies involving team contextual performance have long concluded that team context plays an important role in sustaining teamwork and team functioning. More recently, team contextual performance has been explored to cover aspects of team conflict, team resilience and team trust (Costa, Passos, \& Bakker, 2015; Meneghel, Salanova, \& Martínez, 2016; Cheng \& Cheng, 2017; Hughes, Rigtering, Covin, Bouncken, \& Kraus, 2018). Team contextual performance involves the activities that give impact to an organization's social and psychological environment (Morgeson et al., 2005). Such activities include teammates helping behavior, job dedication, and other reflective actions that can inculcate teamwork. Team contextual performance usually reflects teamwork properties such as acceptance towards suggestions or criticisms, cooperation, communication, team spirit and morale, adaptability, coordination, and acceptance of suggestions or criticisms (Baker \& Salas, 2006). In addition, team contextual performance includes sets of interrelated thoughts, actions, and feelings of team members which are important to the team functioning.

A healthy nursing work environment often includes good and supportive work relationships. In team contextual relationships, the supportive relationship comprises job task support, interpersonal support, team members' compliance, and volunteering for additional duties (Al-Homayan et al., 2013). In a similar way, contextual performance in nursing teams can be demonstrated through the team's personal and social support, and their relationship dimensions (nurse and physician collaboration), which usually lead to better patient outcomes (Pearson et al., 2006). A high performing clinical teams, according to Bleakley (2013), usually reflect high collaborations, tolerance, and understanding of each other's role. All these elements suggest the importance of high team contextual performance in driving teams' success.

In overall, this paper addresses the importance of trust in the contextual linkage of team performance. There has been a dearth of studies that examined trust as a mediator in the relationship between team performance and its predictors. This is more so in the nursing environment. Most studies done on trust treated it as an independent variable and are based on nursepatient relationships with very few studies that examined trust among team members. This paper contributes to prove that team leaders' transformational leadership and team support affects team contextual performance via team trust and that this linkage is important in ensuring quality healthcare delivery. There 
is an emerging importance to establish a workable concept of team trust especially for nursing teams.

\section{LITERATURE REVIEW}

Team trust affects team performance because the former produces quality interactions to pursue team goals. Kalisch et al. (2010) operationalized team trust as the extent to which team members trust each other in communicating ideas and information, and also in valuing, seeking, and giving each other constructive feedback. Team trust relates to a shared perception that team members are willing to take action for the benefit of the team (Kalisch et al., 2010, Kalisch \& Schoville, 2012). The strength of trust that team members have will create a comfortable working environment for them, which in turn, will elevate performance. When team members trust each other, team tasks will be easier to manage and team members will be more driven to accomplish team goals (Gill, Boies, Finegan, \& McNally, 2005).

In a trustworthy relationship, high performing teams usually benefit from positive team leadership. Team leadership is an important aspect of team context as team leaders define team goals, develop, and structure the team in order to accomplish the team's mission (Zaccaro, Rittman, \& Marks, 2001). One particular leadership style that has proven to inspire and motivate team members especially in nursing teams is transformational leadership style (Hutchinson \& Jackson, 2013). Nursing team members perform their duties based on the way leaders' communicate their directives and deal with followers' responses and needs (Hutchinson \& Jackson, 2013).

In addition, team support acts as a positive enhancer in team context as it encourages members' effort to achieve mission success (Drach-Zahavy, 2004). It is highly important for team members to have positive perception that other team members care for their wellbeing (perceived team support), so that they will continue to be motivated to pursue team success (Bishop et al., 2000). In fact, help and support from other members enhanced team performance.

The extant literature indicates that team contextual performance has been studied widely in nursing settings. Examples of works include Brunetto, FarrWharton, and Shacklock (2011), Kalisch et al. (2010), and Kalisch et al. (2009). With the advancement of medical technology, the outbreaks of new diseases, and the prolonged problem of nursing shortage, nursing teams must be able to exert greater contextual performance that are beneficial to the team and the patients at large. Team contextual performance is also essential to the overall team performance because cooperation, helping behaviors, and teamwork explains the nontechnical side of team performance. This attribute is needed to balance the technical aspects brought about by team task performance. As for nursing teams, the way they progress through their social context is crucial in elevating team performance. Nursing teams need to adapt to role changes and increase their effective coordination of care, especially in public hospitals where the numbers of patients are overwhelming and where nursing care has become more specialized (Canales \& Drevdahl, 2014).

A healthy nursing work environment often includes good and supportive work relationships. In team contextual relationships, the supportive relationship comprises job task support, interpersonal support, team members' compliance, and volunteering for additional duties (Al-Homayan et al., 2013). In a similar way, contextual performance in nursing teams can be demonstrated through the team's personal and social support, and their relationship dimensions (nurse and physician collaboration), which usually lead to better patient outcomes (Pearson et al., 2006). A high performing clinical team, according to Bleakley (2013), usually reflect high collaborations, tolerance, and understanding of each other's role. All these elements suggest the importance of high team contextual performance in driving teams' success.

\subsection{The Mediating Role Of Team Trust In The Linkage Between Transformational Leadership, Team Support And Team Contextual Performance}

Trust in a nursing team comes from individual trust and it evolves to the team level through collective processes such as close interactions and increased interdependence (Costa, 2003a; Costa, 2003b). At the individual level, trust is conceptualized as one's expectation that another will behave in a mutually agreed manner (Johns, 1996). At the team level, trust is conceptualized as the extent to which team members confide and rely on other members (Costa, 2003b). The trust in nursing team will enhance the feelings of belongingness to the team, which will heighten its members' motivation to achieve greater performance (Altuntas \& Baykal, 2010). Costa (2003a) stated that team trust occurs as a result of team members' quality interactions, interdependence and participation.

In nursing teams, trust is often work-related and it refers to the ability of team members to rely on the information passed on by others (Johns, 1996; Pask, 1995). Team trust is highly essential in medical situations where it is crucial for nursing teams to be effective in promoting a caring and supportive environment for patient's safety. In nursing care, the attributes of trust will be based on the nurses' interpersonal characteristics including attentiveness, 
caring, coordination, continuity, and competence (Radwin \& Cabral, 2010).

Team context represents the surrounding in which a team will have to work (Tuuli et al., 2012). White and Lean (2008) noted the association between perceived team support and team trust by examining the impact of integrity on the relationship between team members and their leaders. They claimed that the perception of support created an atmosphere of trust that will in turn elevate performance. In addition, Sheng et al. (2010) examined the impact of trust and team support on teamwork behaviors and found that perceived team support positively and significantly influences team trust.

Team trust was also found to be significantly related to transformational leadership. Den Hartog (2003) asserted that team context, through transformational leadership, develops trust via the ideological visions and stimulations of intellectual thoughts. This builds a certain degree of confidence in the followers, which in turn leads to stronger sense of trust.

Therefore, based on the aforementioned tenets highlighting the importance of team contextual performance, this paper analyzed the impact of team trust on the relationships between team transformational leadership, team support and team contextual performance. The hypotheses were as the following:

H1: Team trust will mediate the relationship between perceived team support and team contextual performance.

$\mathrm{H} 2$ : Team trust will mediate the relationship between transformational leadership and team contextual performance.

Figure 1 depicts the model of this study.

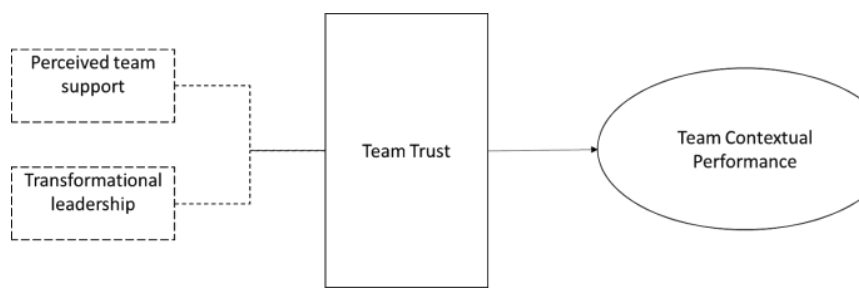

Figure 1 Research model.

\section{METHODS}

Data was collected at the team level, and aggregation of score was done. Self-administered questionnaires were distributed to team leaders and team members in a non-fixed setting, with minimal contact between respondents and the researchers.

\subsection{Study Design And Sample}

This study was conducted among nursing teams located in hospitals in Peninsular Malaysia. 300 nursing teams were involved consisting of 1436 individual nurses. Data were aggregated at the team level similar to the procedure taken by Jayasingam, Ansari, and Jantan (2010). Following Jayasingam, et al. (2010, 2013), 1436 individual scores in this study in accordance to their respective teams (300 teams in total), were tested for consistency in agreement using the r_(WG(J)) index by James et al. (1984). The $r_{-}(\mathrm{WG}(\mathrm{J}))$ index explains the uniformity in team members' ratings in terms of their proportional reduction in error variance (LeBreton \& Senter, 2008).

\subsection{Measurements}

Transformational leadership and team support was measured via a seven-point Likert scale ranging from (1) strongly disagree to (7) strongly agree. There were seven items in the perceived team support scale taken from Bishop et al. (2000). This scale required team members to respond to a series of statements that measured the degree to which employees believe that the team values their contribution and cares for their well-being. The scale's reliability was 0.90 , and the scale was answered by both team leaders and team members.

On the other hand, transformational leadership was measured by a 15-item instrument adapted from Kanste et al. (2007), using a seven-point Likert scale ranging from (1) strongly disagree to (7) strongly agree. This scale tested respondents' perception towards their leaders' idealized attribution, idealized behaviors, individualized consideration, inspirational and intellectual stimulation. The scale's internal consistency ranged from 0.88 to 0.92 and this scale was answered by the team members only.

Team trust was adapted from the Nursing Teamwork Survey (Kalisch et al., 2010). Adaptation were made to suit the context of Malaysian nursing teams. This scale has seven items and was designed to measure team members' sense of trust towards other members. According to Kalisch et al. (2010) and Kalisch and Schoville (2012), trust is the extent to which members trust each other enough to communicate ideas, information, and to value, seek, and give each other constructive feedback. The original reliability for this scale was 0.70 . Team trust was measured using a fivepoint Likert scale ranging from (1) rarely to (5) always. Team trust scale was answered by both team leaders and team members.

Team contextual performance was measured through nine items that reflected interpersonal facilitation, interpersonal helping, job dedication, and 
individual initiative (Morgeson et al., 2005). The reliability for this scale was 0.98 . Team contextual performance scale, using a five-point Likert scale ranging from (1) to (5), were answered by both team leaders and team members.

\subsection{Data Collection Procedure}

A total of 320 sets of questionnaires were distributed to 320 teams. Each set of questionnaires consisted of five individual questionnaires, to be answered by one team leader and a maximum of four team members. In total, 1600 individual questionnaires were distributed to team members. The final sample for analysis involved 300 teams which consisted of 1439 individuals.

In terms of protocol procedures, the Malaysian Ministry of Health required all research involving medical personnel to register via National Medical Research Register (NMRR). After successful registration, the researcher then had to obtain individual approval from twelve state public hospitals throughout Malaysia in seeking the permission to distribute research instruments at their premises. Their approvals via an IA-HOD-IP Form (Investigator Agreement, Head of Department, and Institutional Approval Form) were then submitted online to NMRR to obtain clearance from Medical Research Ethics Committee (MREC). After approval has been granted from MREC, all twelve state hospitals were re-contacted for data collection. In this process, seven state hospitals agreed to continue participation in this study. Three hospitals withdrew participation due to busy schedule and unspecified internal issues. Meanwhile, the remaining two hospitals did not respond to the research invitation although enough time was provided for response.

\section{DATA ANALYSIS}

For the purpose of descriptive data analysis, respondents' demographics and descriptive data such as percentages and frequencies were analyzed using the Statistical Package for Social Science (SPSS) software for Windows (Version 20).

For deeper analysis and hypothesis testing, data was analyzed using the Structural Equation Modelling (SEM) technique using partial least square analysis by SmartPLS 2.0 (Ringle, Wende, \& Will, 2005). In partial least square analysis (thereafter labelled as PLS), measurement model and structural model were evaluated as suggested by Henseler, Ringle, and Sinkovics (2009).

\subsection{Evaluation of the Measurement Model}

Measurement model was established to examine the reliability (item reliability and internal consistency) and validity (convergent validity and discriminant validity) of items. Composite reliability score was computed following the formula coined by Chin (1998) and Hair et al. (2013) using items' loading. The value of composite reliability lies between the values of 0 to 1 , where a higher score reflects a higher level of reliability. The values above 0.7 indicate satisfactory level of reliability (Chin, 1998; Hair et al., 2013). High item reliability represented high correlation between items and the construct (Chin, 1998). After establishing the items' reliability, validity of the measurement model was tested.

Table 1. Composite Reliability (CR) \& Average Variance Extracted (AVE)

\begin{tabular}{|l|l|l|}
\hline Construct & CR & AVE \\
\hline Perceived team support & 0.977 & 0.859 \\
\hline Transformational leadership & 0.980 & 0.766 \\
\hline Team trust & 0.934 & 0.667 \\
\hline Team contextual performance & 0.974 & 0.807 \\
\hline
\end{tabular}

The convergent validity of the model was examined by checking the outer loadings and the AVE of each construct. All outer loadings were significant at above 0.70 , and the AVE of each construct exceeds the 0.50 cut-off value as recommended by Fornell and Larcker (1981) and supported by Hair et al. (2013). This indicated that the items used in this study had an acceptable level of convergent validity.

Then, model was checked for discriminant validity. 2 methods were used. The first one followed the suggestions made by Fornell and Larcker (1981), by examining the correlations among its constructs. Model is said to have discriminant validity if the correlations among each construct are smaller than its AVE square rooted. The second method was done by examining the items in each construct. Chin (1998) asserted that the items in each construct must load higher among themselves more than the loading values of other constructs. The outputs showed that all items loaded higher on their respective constructs.

Table 2. Correlations Among Construct

\begin{tabular}{|l|l|l|l|l|}
\hline Construct & PTS & TFL & TT & TCP \\
\hline $\begin{array}{l}\text { Perceived team } \\
\text { support (PTS) }\end{array}$ & 0.927 & & & \\
\hline $\begin{array}{l}\text { Transformational } \\
\text { leadership (TFL) }\end{array}$ & 0.766 & 0.875 & & \\
\hline Team trust (TT) & 0.672 & 0.587 & 0.817 & \\
\hline $\begin{array}{l}\text { Team contextual } \\
\text { performance (TCP) }\end{array}$ & 0.787 & 0.707 & 0.722 & 0.898 \\
\hline
\end{tabular}




\subsection{Data Aggregation}

After the measurement model has been examined for its reliability and validity, and before the structural model can be further assessed, data at the individual level had to be aggregated to team level. This is in line with the suggestions made by Jayasingam, Ansari, and Jantan (2010), and Jayasingam, Ansari, Ramayah, and Jantan (2013). Jayasingam et al. (2010, 2013) asserted that in a multilevel research analysis (such as organizations or teams), data from individual respondents must be aggregated to a higher level before further analysis can be performed. This is done by combining team members' scores to represent the team's total score. However, before data can be aggregated, all individual data must be checked for their level of inter-rater agreement using the multi-item estimator (also known as the rwjg index) as coined by James, Demaree, and Wolf (1984).

All 300 teams in the data sets of this study had a strong level of agreement ranging from 0.8325 to 0.9940 . In order to proceed with data aggregation, the aggregated value of each data set must exceed the value of 0.70 as suggested by James et al. (1984). The 0.70 cutoff value has also been validated by numerous studies that administered similar method of multilevel analysis (Biemann et al., 2012; LeBreton \& Senter, 2008). Conclusively, based on the value of rwjg scores calculated from the 300 teams involved in this study, all data sets were found eligible for aggregation and further analysis.

\subsection{Assessment of Structural Model}

The role of team trust as a mediator between team characteristics and team performance was tested using the product of coefficients method suggested by MacKinnon et al. (2007). This was done by computing the multiplication effect of two paths $\left(a^{*} b\right)$ where the path estimates will then be divided by a standard error value to determine the significance of the mediation path. Each mediated pathway that has $\mathrm{p}$ value lower than $.05(\mathrm{p}<0.05)$ was deemed significant.

Results from the analysis indicated that, team trust mediated the relationship between perceived team support and team contextual performance $(\beta=0.175$, $\mathrm{p}<0.01$ ), and team trust was also found to mediate the relationship between transformational leadership and team contextual performance $(\beta=0.057, \mathrm{p}<0.05)$.

Variance accounted for (or VAF) was computed to determine the strength of mediation (Hair et al., 2013). The indirect effects of path coefficients were divided by the total values of both direct and indirect effects. Hair et al. (2013) postulated that VAF values of $20 \%$ and above indicate the existence of mediation in the relationships between latent variables. In this study, team trust explained $29.4 \%$ of variance in the relationship between perceived team support and team contextual performance, and $22.7 \%$ of variance in the relationship between transformational leadership and team contextual performance. Thus, based on the VAF percentages as recommended by Hair et al. (2013), which are all above $20 \%$, it can be concluded that team trust substantially mediates the relationship between the independent variables and the dependent variable.

Deeper analysis was done to ensure the fitness of the model. This included predictive relevancy using $\mathrm{Q}^{2}$ and $\mathrm{R}^{2}$ statistics. Using the blindfolding procedure, data sets underwent a repetitive process of cross validation up to a point where each data point has been excluded and reestimated (Hair et al., 2013; Chin, 1998). This procedure is only applied to the endogenous constructs of a model and it reveals the quality of a structural equation model (Tenenhaus, Vinzi, Chatelin, \& Lauro, 2004). Based on Hair et al. (2013) with $Q^{2}$ values ranging from 0.286 to 0.524 , it can be concluded that the structural model of this study has a substantially significant predictive relevance ranging from medium to large. $\mathrm{R}^{2}$ values were also computed. $\mathrm{R}^{2}$ values range from 0 to 1 , with 0 representing complete lack of fit and 1 representing a perfect fit (Bagozzi, 1994). The $\mathrm{R}^{2}$ values of the structural model in this study range from 0.464 to 0.703 indicated that the model is fit for this study.

Finally, the GoF index is computed through the geometric mean of the average communality of all constructs and the average $\mathrm{R}^{2}$ of each endogenous variable (Tenenhaus et al., 2005). The goodness of fit index (GoF) introduced by Tenenhaus et al. (2004) describes how well a structural model fit to predict an observation. The GoF index value for this study is 0.627. Based on the baseline values proposed by Wetzels, Odekerken-Schröder, and Van Oppen, (2009), the GoF value obtained for this study is large. Thus, it can be concluded that the structural model is valid and relevant for this study.

\section{CONCLUSION}

Team context is the surroundings in which a team operates. In this study, team context consists of perceived team support and transformational leadership. It is pivotal that members feel that they are being supported and that their leaders are reflecting transformational behaviors because these feelings will assure the team members that their well-being and interests are taken care of. The positive perceptions that team members have towards other members and their leaders will strengthen their sense of trust, which is important in task executions. Successful task executions will subsequently lead to better team performance. 
The result of this study showed that team trust mediated the relationship between perceived team support and team contextual performance $(\beta=0.175$, $\mathrm{p}<0.01)$. This finding indicates that team members who perceive team support will reciprocate through team trust, which in turn, leads to greater contextual performance. This also means that the perception team members have towards being supported increases their trust as they feel acknowledged and appreciated (White \& Lean, 2008).

The finding of this study concurs with the nature of nursing teams in public hospitals. As Malaysian public hospitals are becoming more crowded and overwhelmed with patients' demands (Ahmad \& Oranye, 2010), nursing teams must be able to support each other in handling medical situations. Patients' demands and work demands can be exhausting to team members, thus they must be able to display great level of support and trust among themselves in order to achieve greater team performance. Results also indicated that team trust mediates the relationship between transformational leadership and team contextual performance $(\beta=0.057$, $\mathrm{p}<0.05)$.

The findings of this study concerning the role of team trust in the relationship between transformational leadership and team contextual performance is in harmony with earlier studies done by Den Hartog (2003). These studies found that the perception that team members have towards their leaders' transformational leadership style strengthen the feelings of team trust and further enhance contextual performance. This is because, team members will often turn to their leaders for sense of direction especially in making final decisions. The findings of this study proves that when nursing team members exhibit similar behaviors, they will feel more inclined to trust each other and perform better. In handling everyday activities in a hospital, nursing team members will demonstrate positive team behaviors that will accelerate performance. Nurse members who are accustomed to each other will perform greatly over members who are not.

\section{ACKNOWLEDGMENT}

We would like to thank the Director General of Health Malaysia for his permission to publish this article.

\section{REFERENCES}

[1] Ahmad N, Oranye NO. Empowerment, job satisfaction and organizational commitment: comparative analysis of nurses working in
Malaysia and England. Journal of nursing management. $2010 \mathrm{Jul}$;18(5):582-91.

[2] Al-Homayan AM, Shamsudin FM, Subramaniam C, Islam R. Impacts of job performance level on nurses in public sector hospitals. American Journal of Applied Sciences. 2013 Sep 1;10(9):1115.

[3] Altuntas S, Baykal U. Relationship between nurses' organizational trust levels and their organizational citizenship behaviors. Journal of Nursing Scholarship. 2010 Jun 1;42(2):186-94.

[4] Bagozzi RP. Structural equation models in marketing research: Basic principles. Principles of marketing research. 1994;3(1):7-385.

[5] Baker DP, Day R, Salas E. Teamwork as an essential component of high-reliability organizations. Health services research. 2006 Aug;41(4p2):1576-98.

[6] Biemann T, Cole MS, Voelpel S. Within-group agreement: On the use (and misuse) of rWG and rWG $(\mathbf{J})$ in leadership research and some best practice guidelines. The Leadership Quarterly. 2012 Feb 1;23(1):66-80.

[7] Bishop JW, Scott KD, Burroughs SM. Support, commitment, and employee outcomes in a team environment. Journal of management. 2000 Dec;26(6):1113-32.

[8] Bleakley, A. (2013). Working in "teams" in an era of "liquid" healthcare: What is the use of theory?. Journal of Interprofessional Care, 27(1), 18-26.

[9] Brunetto Y, Farr-Wharton R, Shacklock K. Supervisor-nurse relationships, teamwork, role ambiguity and well-being: Public versus private sector nurses. Asia Pacific Journal of Human Resources. 2011 Jun;49(2):143-64.

[10] Canales MK, Drevdahl DJ. Community/public health nursing: Is there a future for the specialty? Nursing Outlook. 2014 Nov 1;62(6):448-58.

[11] CHENG J, CHENG FL. A Study of the Impact of Trust among $\mathrm{R} \& \mathrm{D}$ Team Members on their Performance. DEStech Transactions on Social Science, Education and Human Science. 2017(msie).

[12] Chin WW. The partial least squares approach to structural equation modeling. Modern methods for business research. 1998 Jan;295(2):295-336.

[13] Costa AC. Understanding the nature and the antecedents of trust within work teams. The trust process in organizations: Empirical studies of the 
determinants and the process of trust development. 2003:105-24

[14] Costa AC. Work team trust and effectiveness. Personnel review. 2003 Oct 1;32(5):605-22.

[15] Costa PL, Passos AM, Bakker AB. Direct and contextual influence of team conflict on team resources, team work engagement, and team performance. Negotiation and Conflict Management Research. 2015 Nov;8(4):211-27.

[16] Den Hartog D. Trusting others in organizations: Leaders, management and co-workers. The trust process in organizations: Empirical studies of the determinants and the process of trust development. 2003:125-46.

[17] Drach-Zahavy A. Exploring Team Support: The Role of Team's Design, Values, and Leader's Support. Group Dynamics: Theory, Research, and Practice. 2004 Dec;8(4):235.

[18] Fornell C, Larcker DF. Structural equation models with unobservable variables and measurement error: Algebra and statistics. 1981 Feb;18(1): 3950.

[19] Gill H, Boies K, Finegan JE, McNally J. Antecedents of trust: Establishing a boundary condition for the relation between propensity to trust and intention to trust. Journal of business and psychology. 2005 Apr 1;19(3):287-302.

[20] Hair JF, Ringle CM, Sarstedt M. Partial least squares structural equation modeling: Rigorous applications, better results and higher acceptance. Long range planning. 2013 Mar 14;46(1-2):1-2.

[21] Henseler J, Ringle CM, Sinkovics RR. The use of partial least squares path modeling in international marketing. InNew challenges to international marketing 2009 Mar 6 (pp. 277-319). Emerald Group Publishing Limited.

[22] Hughes M, Rigtering JC, Covin JG, Bouncken RB, Kraus S. Innovative behaviour, trust and perceived workplace performance. British Journal of Management. 2018 Oct;29(4):750-68.

[23] Hutchinson M, Jackson D. Transformational leadership in nursing: towards a more critical interpretation. Nursing inquiry. 2013 Mar 1;20(1):11-22.

[24] James LR, Demaree RG, Wolf G. Estimating within-group interrater reliability with and without response bias. Journal of applied psychology. 1984 Feb;69(1):85.

[25] Jayasingam S, Ansari MA, Jantan M. Influencing knowledge workers: the power of top management.
Industrial Management \& Data Systems. $2010 \mathrm{Feb}$ 2;110(1):134-51.

[26] Jayasingam S, Ansari MA, Ramayah T, Jantan M. Knowledge management practices and performance: are they truly linked?. Knowledge Management Research \& Practice. 2013 Aug 1;11(3):255-64.

[27] Johns JL. A concept analysis of trust. Journal of Advanced Nursing. 1996 Jul;24(1):76-83.

[28] Kalisch BJ, Lee H, Salas E. The development and testing of the nursing teamwork survey. Nursing research. 2010 Jan 1;59(1):42-50.

[29] Kalisch BJ, Weaver SJ, Salas E. What does nursing teamwork look like? A qualitative study. Journal of Nursing Care Quality. 2009 Oct 1;24(4):298-307.

[30] Kalisch B, Schoville R. It takes a team. AJN The American Journal of Nursing. 2012 Oct 1;112(10):50-4.

[31] Kanste O, Miettunen J, Kyngäs H. Psychometric properties of the Multifactor Leadership Questionnaire among nurses. Journal of Advanced Nursing. 2007 Jan;57(2):201-12.

[32] LeBreton JM, Senter JL. Answers to 20 questions about interrater reliability and interrater agreement. Organizational research methods. 2008 Oct;11(4):815-52.

[33] MacKinnon DP, Fairchild AJ, Fritz MS. Mediation analysis. Annu. Rev. Psychol.. 2007 Jan 10;58:593-614.

[34] Meneghel I, Salanova M, Martínez IM. Feeling good makes us stronger: How team resilience mediates the effect of positive emotions on team performance. Journal of Happiness Studies. 2016 Feb 1;17(1):239-55.

[35] Morgan Tuuli M, Rowlinson S, Fellows R, Liu AM. Empowering the project team: impact of leadership style and team context. Team Performance Management: An International Journal. 2012 Jun 8;18(3/4):149-75.

[36] Morgeson FP, Reider MH, Campion MA. Selecting individuals in team settings: The importance of social skills, personality characteristics, and teamwork knowledge. Personnel psychology. 2005 Sep;58(3):583-611.

[37] Pearson A, Porritt KA, Doran D, Vincent L, Craig D, Tucker D, Long L, Henstridge V. A comprehensive systematic review of evidence on the structure, process, characteristics and composition of a nursing team that fosters a 
healthy work environment. International Journal of Evidence-Based Healthcare. 2006 Jun;4(2):118-59.

[38] Radwin LE, Cabral HJ. Trust in Nurses Scale: Construct validity and internal reliability evaluation. Journal of Advanced Nursing. 2010 Mar 1;66(3):683-9.

[39] Ringle CM, Wende S, Will A. SmartPLS 2.0 (beta). Hamburg, Germany.

[40] Sheng CW, Tian YF, Chen MC. Relationships among teamwork behavior, trust, perceived team support, and team commitment. Social Behavior and Personality: a international journal. 2010 Nov 1;38(10):1297-305.

[41] Tenenhaus M, Vinzi VE, Chatelin YM, Lauro C. PLS path modeling. Computational statistics \& data analysis. 2005 Jan 1;48(1):159-205.
[42] Wetzels M, Odekerken-Schröder G, Van Oppen C. Using PLS path modeling for assessing hierarchical construct models: Guidelines and empirical illustration. MIS quarterly. 2009 Mar 1:177-95.

[43] White DW, Lean E. The impact of perceived leader integrity on subordinates in a work team environment. Journal of Business Ethics. 2008 Sep 1;81(4):765-78.

[44] Zaccaro SJ, Rittman AL, Marks MA. Team leadership. The leadership quarterly. 2001 Dec 1;12(4):451. 